\title{
Explorando a Utilização de Storyboard em um Ambiente Tangível de Apoio à Comunicação Alternativa e Aumentativa
}

\author{
Eliana Alves Moreira' ${ }^{1,2}$, Eliane de S. Ramos ${ }^{3,4}$, Luciana Wolff ${ }^{3}$, Catia de T. \\ Bortolini $^{3}$, E. Paula Cavalcanti ${ }^{3}$, Leila A. D. Pinto ${ }^{3}$, Maria do Carmo B. Bruschini ${ }^{3}$, \\ Maria Luisa P. Benedetti ${ }^{3}$, Marisol R. P. de Oliveira ${ }^{3}$, M. Cecília C. Baranauskas ${ }^{2}$ \\ ${ }^{1}$ Instituto Federal de São Paulo (IFSP) \\ Av. Salgado Filho, 3501 - 07115-000 - Guarulhos - SP - Brasil \\ ${ }^{2}$ Instituto de Computação; ${ }^{4}$ Faculdade de Educação \\ Universidade Estadual de Campinas (UNICAMP) \\ Av. Albert Einstein, 1251 - 13.083-852; Av. Bertrand Russell, 801 -13083-865- \\ Campinas - SP - Brasil \\ ${ }^{3}$ Secretaria de Educação do Município de Amparo \\ Av. Bernardino de Campos, 705 - 13900-400 - Amparo - SP - Brasil
eliana.moreiradifsp.edu.br, \{ccrtbortilini, epcavalcanti, ladpinto, mcbbruschini, mlpbenedetti, mrpoliveira\} eamparo.sp.gov.br,
souzaramos80@gmail.com, luwolff@uol.com.br, cecilia@ic.unicamp.br

\begin{abstract}
Literature has presented different approaches to the use of contemporary technologies to aid communication. This work contributes with a computational environment based on tangible interaction, as an Augmentative and Alternative Communication technology, that was explored by special needs education professionals, through participative Workshops. Results show how these professionals make sense and suggest changes in the design of the environment to fit the activities carried out in inclusive classrooms and special attendance. We implemented a new version based on these suggestions, which was used by the professionals in three different types of activities: storytelling, action sequencing and challenge answering.
\end{abstract}

Resumo. A literatura apresenta diferentes propostas de uso de tecnologia contemporânea como auxílio à comunicação. Este trabalho contribui com um ambiente computacional de interação tangível, como tecnologia de Comunicação Alternativa e Aumentativa, que foi explorado por profissionais de educação especial, por meio de Oficinas participativas. Resultados mostram como esses profissionais fazem sentido e sugerem alterações no design do ambiente para melhor adequá-lo às atividades que são realizadas nas salas de aulas inclusivas e de atendimento especial. Com base nessas sugestões foi implementada nova versão que foi utilizada pelas participantes em três tipos de atividades: contação de histórias, sequenciação de ações e desafio.

\section{Introdução}

Em nossas pesquisas, temos realizado atividades dentro da perspectiva do design para todos com o objetivo de possibilitar a construção e a avaliação incrementais de um 
VII Congresso Brasileiro de Informática na Educação (CBIE 2018)

Anais do XXIX Simpósio Brasileiro de Informática na Educação (SBIE 2018)

ambiente tecnológico que utiliza interação tangível, como suplemento à comunicação de alunos que não se fazem entender pela fala, matriculados em escolas comuns. Tais alunos frequentam o Atendimento Educacional Especializado - $\mathrm{AEE}^{1}$. O propósito de trabalhar com ambiente baseado nessas tecnologias tangíveis ocorre pelo fato de que nesse ambiente o computador "desaparece" e o usuário pode fazer uso do sistema de forma mais natural, em relação ao uso de dispositivos tradicionais de interação como o mouse e o teclado. Ainda, o uso de materiais tangíveis estimula múltiplos sentidos e o desenvolvimento de funções cognitivas e habilidades de percepção com o envolvimento do corpo [Garzotto e Bordogna 2010].

Quando um aluno fala e o seu interlocutor não entende o que ele quer comunicar, ou ainda, quando um aluno não fala, é preciso criar alternativas que possibilitem uma interação, no ambiente escolar e fora dele, sem barreiras comunicacionais. Nesse sentido, um conjunto de ferramentas e estratégias que o aluno, bem como seus colegas e professores podem utilizar enquanto se comunicam é a Comunicação Alternativa e Aumentativa - $\mathrm{CAA}^{2}$, que funciona como complemento e/ou substituição da fala para ampliar as possibilidades de comunicação [ASHA 2016]. Denomina-se o conjunto de componentes da CAA de "Sistemas de Comunicação Alternativa e Aumentativa", podendo ser manuais (gestos, alfabeto digital e português sinalizado, além de outros marcadores gramaticais complexos) e gráficos (fotos, desenhos de alta iconicidade, símbolos gráficos e a ortografia tradicional) [Sonza et al. 2013].

Dentro do contexto de crianças usuárias de sistemas alternativos de comunicação, Tenor \& Deliberato (2004) realizaram um estudo sobre estratégias de mediação para o conto e reconto de histórias para alunos surdos. Segundo esses autores, estudos desenvolvidos evidenciaram a necessidade de estimular as habilidades narrativas nessas crianças, uma vez que "a escuta de histórias estimula a imaginação, educa, instrui, desenvolve habilidades cognitivas, dinamiza o processo de leitura e escrita, além de ser uma atividade interativa que potencializa a linguagem infantil". Ainda de acordo com esses autores, sistemas visuais (gráficos) "colaboram na produção da narrativa e poderiam ser um instrumento favorecedor para aquisição da narrativa de alunos surdos, em função dos marcadores visuais oferecidos para as questões de sentido e de organização do pensamento", o que certamente podemos estender para pessoas em situação de deficiência que são menos desfavorecidas quando contam com recursos que tornam os ambientes mais acessíveis.

Pesquisadores têm estudado sistemas gráficos e narrativas a partir de tecnologias tangíveis. Garzotto \& Bordogna (2010) propuseram o Talking Paper, um ambiente que possui uma abordagem para associar conteúdos visuais físicos com recursos multimídia. $\mathrm{Na}$ proposta desses autores, elementos baseados em papéis são equipados com tecnologia de etiquetas de Radio Frequency Identification (RFID) para se conectar aos

\footnotetext{
${ }^{1}$ Serviços de apoio especializado da Educação Especial, voltados a eliminar as barreiras que possam obstruir o processo de escolarização de estudantes com deficiência, transtornos globais do desenvolvimento e altas habilidades ou superdotação (Brasil, 2011; Brasil, 2007)

2 No Brasil, entre as diversas áreas de estudo, não existe um consenso sobre termos para Augmentative and Alternative Communication, originário do inglês, sendo comum encontrar, os termos Comunicação Suplementar e Alternativa, Comunicação Alternativa e Ampliada, entre outros [Chun 2009].
} 
VII Congresso Brasileiro de Informática na Educação (CBIE 2018)

Anais do XXIX Simpósio Brasileiro de Informática na Educação (SBIE 2018)

recursos multimídia, tais como controles multimídia de comportamento, vídeos, música e voz, de modo a organizar uma narrativa de uma história conhecida (ao juntar cenas para formar um todo em uma ordem significativa) e construir associações entre o componente da história e os símbolos gráficos de CAA correspondentes. No ambiente do Talking Paper, o participante utiliza papéis com cenas de uma história pré-definida, que está ligada a um vídeo dessa mesma cena, limitando sua utilização aos papéis e vídeos criados. O ambiente que propomos é composto por cartões com símbolos gráficos de CAA, que podem ser combinados para trabalhar com narrativas, sem que devam corresponder à lógica de uma história pré-definida.

Hengeveld, Hummels, Balkom, Voort, \& Moor (2013) projetaram o Linguabytes, um sistema modular composto de materiais lúdicos para leitura de histórias interativas e exercícios linguísticos para crianças com dificuldades na comunicação, acompanhadas de seus cuidadores ou responsáveis. O protótipo de LinguaBytes consiste em módulos para entrada, saída e controle, juntamente com materiais tangíveis para entrada, palavras e etiquetas RFID programáveis para histórias e exercícios, além de fundos temáticos tangíveis; cada um desses deve ser inserido no módulo base para pré-carregar as histórias, jogos e exercícios. Por ser um ambiente composto por módulos físicos construídos a partir de sensores e atuadores, torna-se difícil a sua replicação; em nosso ambiente computacional propomos apenas o uso de cartões e leitor RFID.

Este trabalho compartilha nossa experiência no estudo e extensão do Tan2Talk, um ambiente computacional tangível de apoio à comunicação. O objetivo do trabalho é propor formas de eliminar barreiras comunicacionais para alunos com necessidades complexas de comunicação, podendo contribuir com o desenvolvimento da linguagem, da criatividade, de noções temporais, aprendizado de regras etc. Dentro de uma abordagem de design participativo, contamos com a colaboração de professoras que realizam o AEE e tem experiência no trabalho com alunos que não se fazem entender pela fala. As ideias descritas neste trabalho refletem as maneiras como essas professoras propuseram o uso do ambiente, visando aspectos de comunicação alternativa e aumentativa e de design universal subjacentes ao trabalho com narrativas.

As próximas seções apresentam o contexto dessa pesquisa e o ambiente utilizado, seguida da metodologia das Oficinas participativas, do design da funcionalidade de narrativas com propostas para sua aplicação e discussão. Por fim, concluímos.

\section{Contexto da Pesquisa}

Em nossos estudos temos realizado Oficinas ${ }^{3}$ participativas ao longo de vários semestres, em colaboração com a Divisão de Educação Infantil e Complementar - DEdIC (http://www.dgrh.unicamp.br/dedic) da Universidade Estadual de Campinas (UNICAMP), na unidade do Programa de Desenvolvimento e Integração da Criança e do Adolescente - Prodecad (cenário 1), que oferece educação complementar a crianças de 6 a 14 anos, em horário de contraturno ao ensino regular. Outra parceria é a Secretaria de Educação do município de Amparo (cenário 2), estado de São Paulo

\footnotetext{
${ }^{3}$ Projeto aprovado pelo Comitê de Ética em Pesquisa (UNICAMP), sob número 32213314.8.0000.5404.
} 
VII Congresso Brasileiro de Informática na Educação (CBIE 2018)

Anais do XXIX Simpósio Brasileiro de Informática na Educação (SBIE 2018)

[Amparo 2016], mais especificamente escolas onde, para oferta do AEE, existem Salas de Recursos Multifuncionais ${ }^{4}$ [Brasil 2011].

Nessas Oficinas participativas o conhecimento é gerado e retroalimentado em ciclos de design pela visão e necessidade dos participantes (pessoas interessadas) por meio de cenários da vida real. Ao longo dessas Oficinas, idealizamos e implementamos um ambiente tangível para apoio à comunicação alternativa e aumentativa, que foi inicialmente projetado para ser utilizado em forma de jogo de adivinhações. Sua representação foi baseada em sistemas gráficos de CAA e em observações realizadas por meio de duas visitas a Salas de Recursos Multifuncionais da cidade de Amparo. A Figura 1 contém dois exemplos de sistemas gráficos preparados (e personalizados) para alunos que frequentam as salas de recursos multifuncionais daquela cidade.
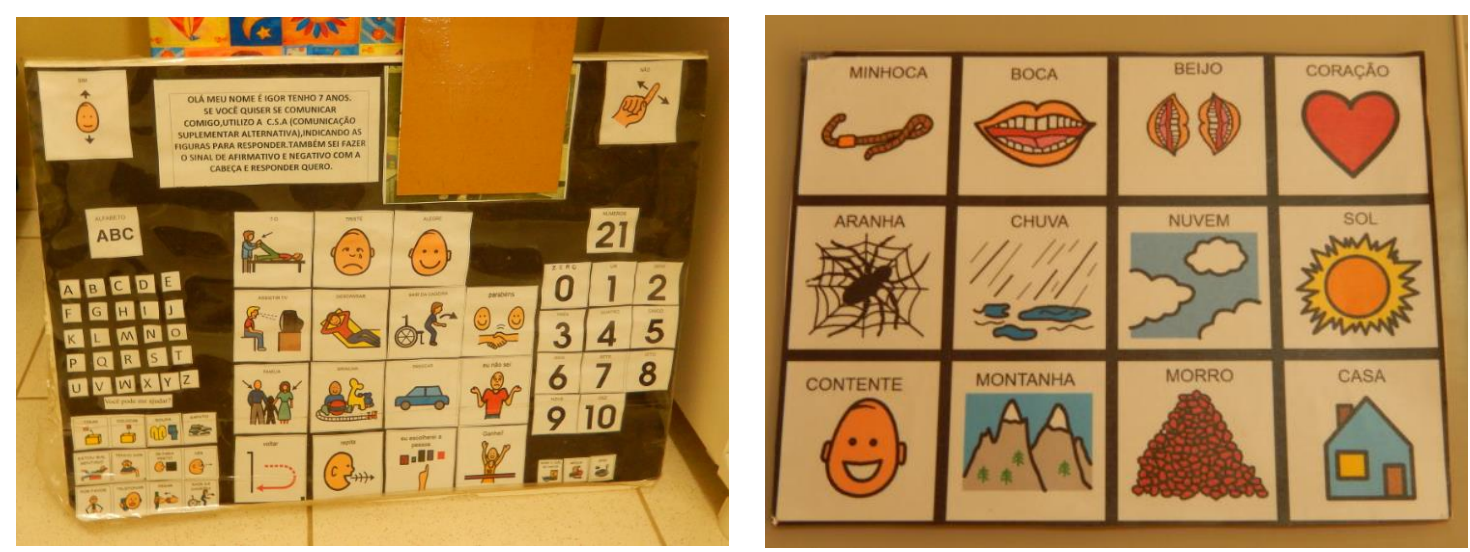

Figura 1. Exemplos de sistemas gráficos de CAA utilizados nas salas de recursos multifuncionais de Amparo.

Em um primeiro momento de nossas pesquisas, realizamos diversas Oficinas com o ambiente em espaço educativo do Prodecad (cenário 1). Nessas Oficinas trabalhamos com professoras e crianças (Figura 2); nenhuma pessoa encontrava dificuldades para se fazer entender pela fala. Resultados dessas Oficinas foram apresentados anteriormente [Moreira e Baranauskas 2016]. Além disso, realizamos também Oficinas para verificar a eficácia do vocabulário utilizado nesse sistema quanto a capacidade de proporcionar a comunicação entre as pessoas em relação a temáticas específicas; resultados culminaram no redesign do ambiente, para estender a comunicação a um maior número de pessoas.

Dando continuidade às nossas pesquisas, realizamos um segundo momento de nossas Oficinas, que aconteceu com professoras de educação especial (cenário 2), que realizam o AEE com alunos que vivem desvantagens na comunicação. As professoras utilizaram o ambiente já redesenhado de acordo com as sugestões realizadas nas Oficinas do cenário 1. Este trabalho detalha nas próximas seções os acontecimentos de duas Oficinas ocorridas no cenário 2.

\footnotetext{
${ }^{4}$ Ambientes dotados de equipamentos, mobiliários e materiais didáticos e pedagógicos para a oferta do Atendimento Educacional Especializado [Brasil 2011].
} 

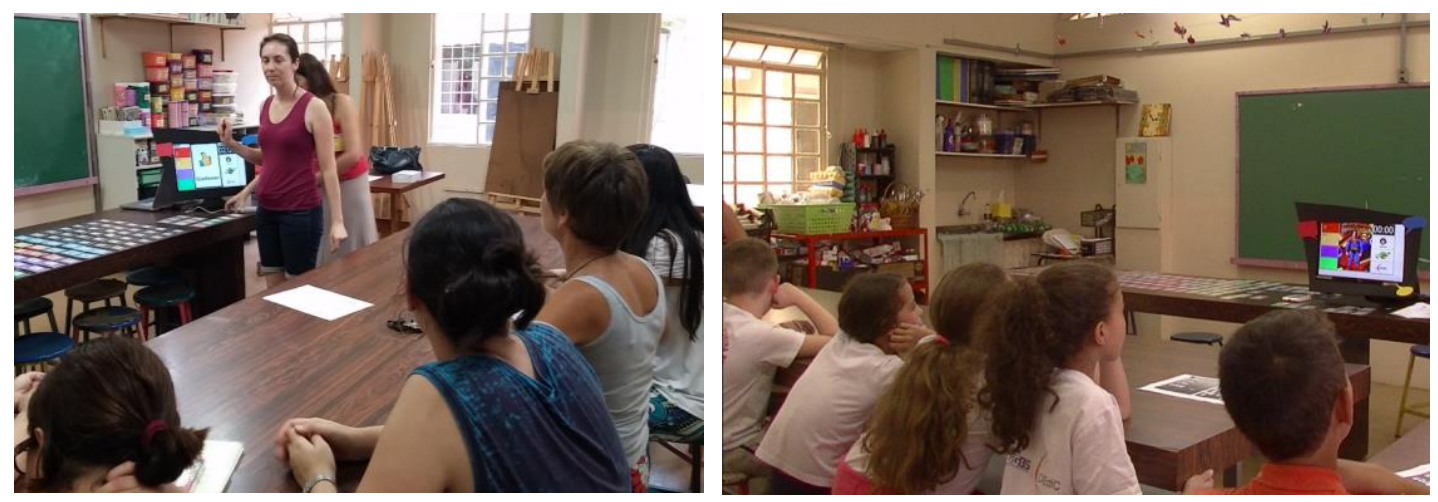

Figura 2. Oficinas realizadas com professoras e crianças (cenário 1)

\subsection{O ambiente computacional tangível para apoio à comunicação}

O ambiente para apoio à comunicação apresenta tecnologia tangível, por meio de etiquetas RFID, acessível às diferentes possibilidades de comunicação e explorada em benefício da comunicação e interação social de forma criativa e lúdica para a maior extensão possível de usuários [Moreira e Baranauskas 2016]. O ambiente possui cartões com figuras pictográficas de alta iconicidade, sendo 188 "Cartões de Comunicação" e 22 "Cartões de Eventos", esses últimos utilizados para controlar ações gerenciais do software. Cada cartão possui representação em Braille em seu verso e uma vocalização associada, ativada quando o cartão é lido. Ainda, o ambiente possui um Modo de Gerenciamento [Moreira e Baranauskas 2018] que permite a criação de novos cartões. A Figura 3 demonstra o ambiente e contém exemplos dos cartões de comunicação e de eventos nele utilizados.
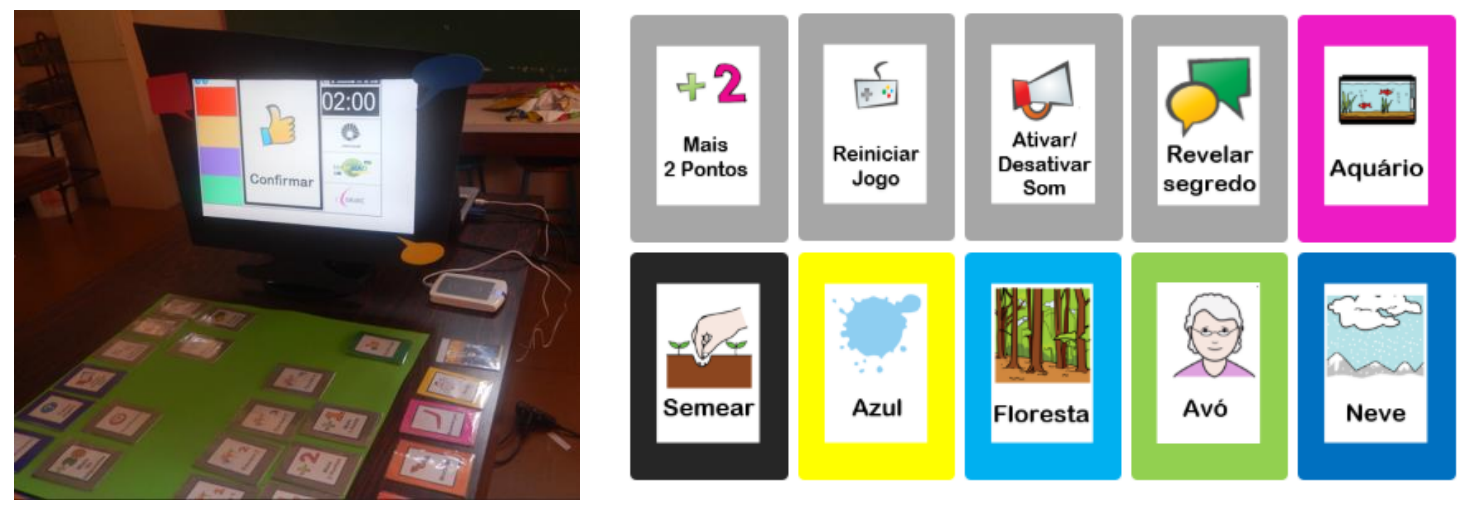

Figura 3. À esquerda, ambiente computacional tangível de apoio à comunicação; à direita, exemplos de cartões de comunicação.

O ambiente foi concebido inicialmente para ser utilizado em um Modo de Jogo (no caso, de adivinhações), onde um participante sorteia um tema e então apresenta, por meio do ambiente, os cartões de comunicação que julga representativos para comunicar o tema, que deve ser "adivinhado" pelos demais participantes do jogo.

\section{Oficinas participativas com professoras que realizam o AEE (cenário 2)}

Conduzimos duas Oficinas com cinco professoras e uma coordenadora de educação especial, além de duas assessoras (uma especialista em LIBRAS e a outra especialista 
VII Congresso Brasileiro de Informática na Educação (CBIE 2018)

Anais do XXIX Simpósio Brasileiro de Informática na Educação (SBIE 2018)

em CAA) do Programa de Educação Inclusiva da rede municipal de educação de Amparo, estado de São Paulo. Cada uma das Oficinas, teve duração de duas horas.

Na primeira Oficina, que chamamos de "Oficina Jogo", as participantes utilizaram o ambiente computacional tangível para apoio à comunicação sob a forma de jogo de adivinhações, modo como foi inicialmente desenvolvido. Após o jogo, as participantes fizeram uma avaliação, onde deram sugestões de outras formas que o ambiente poderia ser utilizado visando a comunicação alternativa e aumentativa, tendo como base as atividades que elas desenvolvem com as crianças do Atendimento Educacional Especializado. Analisando as respostas, percebemos que elas consideraram que essa proposta teria potencial para eliminar barreiras comunicacionais quando alunos que não se fazem entender pela fala, desejassem expressar sentimentos, preferências, opiniões, questionamentos, entre outros. Essas professoras destacaram ainda, que a possibilidade de comunicar com mais precisão o conteúdo desejado, pode contribuir com o desenvolvimento da linguagem, da criatividade, da capacidade de lidar com emoções e frustrações, de noções temporais, aprendizado de regras, dentre outros conteúdos.

Considerando a nossa proposta de desenvolvimento incremental do ambiente, fizemos um estudo para resolver qual a melhor forma de modificar o ambiente de modo a atender as sugestões das participantes realizadas nas "Oficina Jogo". Os detalhes desse estudo, bem como a segunda Oficina, que denominamos de "Oficina Storyboard", onde aplicamos as modificações realizadas, estão descritos em mais detalhes a seguir.

\section{Design do Modo de Storyboard}

Para adequar o ambiente computacional tangível para apoio a comunicação às sugestões que as professoras haviam feito na "Oficina Jogo", idealizamos o Modo de Storyboard.

O storyboard é um guia visual que retrata as principais cenas de um produto audiovisual de forma rápida e objetiva, uma espécie de "história em quadrinhos" que apresenta o conteúdo de um material, na maioria das vezes, audiovisual; porém é utilizado também para retratar sequências de conteúdos em disciplinas escolares, entre outros. Geralmente, a imagem de um storyboard precisa transmitir uma impressão mais fiel de uma imagem real, sem, no entanto, determinar muitos detalhes, sendo importante transmitir a sequência e clima de uma cena. No nosso ambiente, a intenção de uso dessa ferramenta é oferecer uma forma de organizar ideias de modo a trabalhar narrativas com as crianças dentro do tema proposto pelas professoras. Para isso propusemos uma adaptação da ferramenta, onde uma cena é composta por vários quadros do storyboard, cada um deles associado a um cartão do ambiente computacional. Por exemplo, enquanto na abordagem tradicional de um storyboard a cena de um menino conversando com seus pais ocuparia um quadro com todos os personagens e recursos visuais que retratassem o clima da cena, em nossa proposta de storyboard, essa cena poderia ser retratada em um quadro com a imagem do menino, outro com a imagem da ação de falar e outros dois com imagens de seu pai e sua mãe, respectivamente. Uma vez que o Modo de Storyboard apresenta-se como um plano "em branco", as crianças podem usar os cartões na ordem que desejarem.

Em termos de abordagem pedagógica, o trabalho com narrativas por meio de storyboard baseia-se na abordagem construcionista, de Seymour Papert [Papert 1980], 
VII Congresso Brasileiro de Informática na Educação (CBIE 2018)

Anais do XXIX Simpósio Brasileiro de Informática na Educação (SBIE 2018)

que considera que a relação ensino e aprendizagem é mais eficaz quando o aprendiz experimenta a construção de um produto significativo para ele.

No sistema proposto, o Modo de Storyboard mantém as características do Modo de Jogo quanto à vocalização dos cartões e à apresentação das imagens correspondentes quando o cartão é aproximado ao leitor de RFID. A Figura 4 apresenta um exemplo de utilização do Modo de Storyboard e, ainda, como estão divididas as áreas da tela. $\mathrm{Na}$ área (a) é sempre apresentada a imagem referente ao último cartão lido. Em (b), a sequência dos cartões lidos é apresentada, limitada a 24 imagens. O item (c) apresenta uma área onde é possível configurar o ambiente; pode-se ativar ou desativar o som e o ícone da "casa" apresenta a tela inicial do modo, porém não apaga as imagens dos quadros da área de storyboard. Para apagar os quadros dessa área, é necessária a leitura do cartão "Reiniciar". Para apagar um quadro, deve-se utilizar o cartão "Desfazer", que apaga sempre o último quadro na área de storyboard com uma figura apresentada.

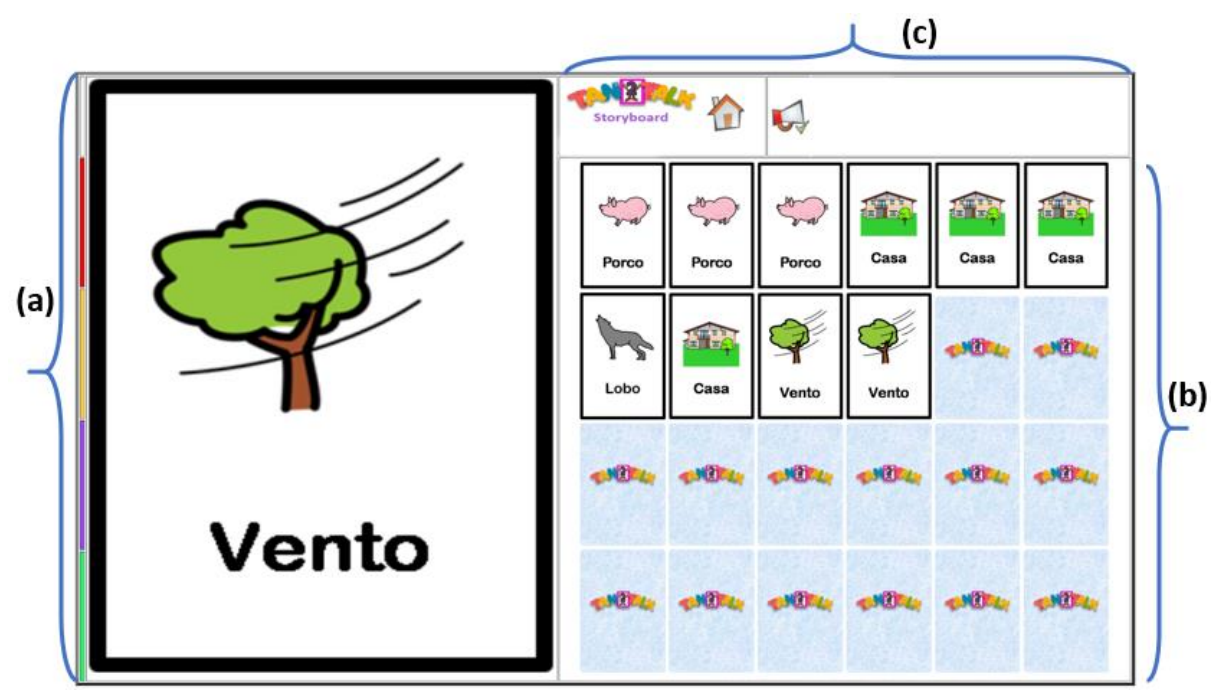

Figura 4. Tela do Modo de Storyboard: (a) imagem do último cartão lido; (b) área do storyboard; (c) área de configuração.

\subsection{Aplicação prática do Modo de Storyboard}

Realizamos uma Oficina do cenário 2, onde se utilizou o Modo de Storyboard. A atividade consistiu na elaboração, pelas participantes, de cenários onde o modo poderia ser aplicado junto aos alunos visando eliminar barreiras comunicacionais. As participantes trabalharam em duplas. Cada dupla deveria propor uma atividade que poderia ser realizada em turmas comuns, ou no AEE, caso a professora de educação especial estivesse avaliando as possibilidades de eliminar barreiras comunicacionais com seu aluno. Cada proposta continha a metodologia, planejamento, objetivos e resultados esperados. As proponentes de cada atividade, além de elaborá-la também a aplicaram durante a mesma Oficina, onde as demais participantes realizavam as atividades que cabiam às crianças. Foram feitas três propostas de atividade.

- Proposta de Atividade 1: Desafio

Duas participantes da Oficina propuseram uma atividade de desafio, cujo objetivo seria descobrir o que se estava comunicando, por meio da narrativa (feita com os cartões de comunicação) de uma história ou fato, por exemplo. Conforme proposta, o tema 
VII Congresso Brasileiro de Informática na Educação (CBIE 2018)

Anais do XXIX Simpósio Brasileiro de Informática na Educação (SBIE 2018)

tratado na atividade seria delimitado e combinado previamente entre todos os participantes; por exemplo, o tema poderia se tratar de histórias infantis, situações do cotidiano etc. Entre os objetivos estão a interação por pares (no caso de a atividade ser realizada em grupo), e no contexto da comunicação alternativa e aumentativa, a capacidade de estabelecer relações das imagens dos cartões de comunicação com coisas ou situações do mundo e em seguida com alguma história conhecida, ampliando possibilidades de comunicação e associação de ideias. Essa proposta se diferencia do jogo de nosso ambiente inicial pelo fato de não existir o fator competição envolvido e por todas as figuras escolhidas estarem visíveis; no jogo, a projeção é apenas a da última figura lida.

- Proposta de Atividade 2: Contação de história

Nessa proposta, as participantes criaram uma atividade onde a(s) criança(s) contariam ou recontariam uma história previamente contada por alguma pessoa, seja de própria autoria dessa pessoa ou baseada em livros, vídeos, cantigas etc. Os objetivos cognitivos a serem trabalhados em sala de aula comum seriam a compreensão da história e organização do pensamento; no contexto da CAA, a capacidade de comunicar e expressar a história. A contação da história pode ser feita individualmente ou em grupo. Nessa atividade, espera-se que as crianças consigam identificar os personagens que pertencem à história, identificar os acontecimentos e organizá-los, além de trabalhar com o conceito de começo-meio-fim. Durante a aplicação prática, as participantes contavam trechos da história a medida que iam escolhendo os cartões relacionados ao trecho. Do ponto de vista de pessoas que têm dificuldade em verbalizar, esse exercício estimula a fala [Moita et al. 2017].

- Proposta de Atividade 3: Sequência de ações

Nessa atividade proposta, o objetivo é trabalhar com sequência de ações, seja ela uma situação-problema, uma sequência didática, uma sequência de apoio à realização de atividades (por exemplo, atividades a realizar após usar o banheiro) etc. A narrativa com os cartões de comunicação seria utilizada para dar comandos, de maneira a promover a associação, pela(s) criança(s) entre a ação e os símbolos dos cartões de comunicação. A Figura 5 apresenta um momento da realização da atividade pelas suas proponentes; no exemplo, à direita, a intenção era retratar a sequências de ações para "andar de motoca no jardim". Como não havia um cartão de comunicação que retratava a figura direta de uma motocicleta, as participantes utilizaram a figura de uma "carruagem", de modo que as demais participantes fizessem associação com a "motoca".
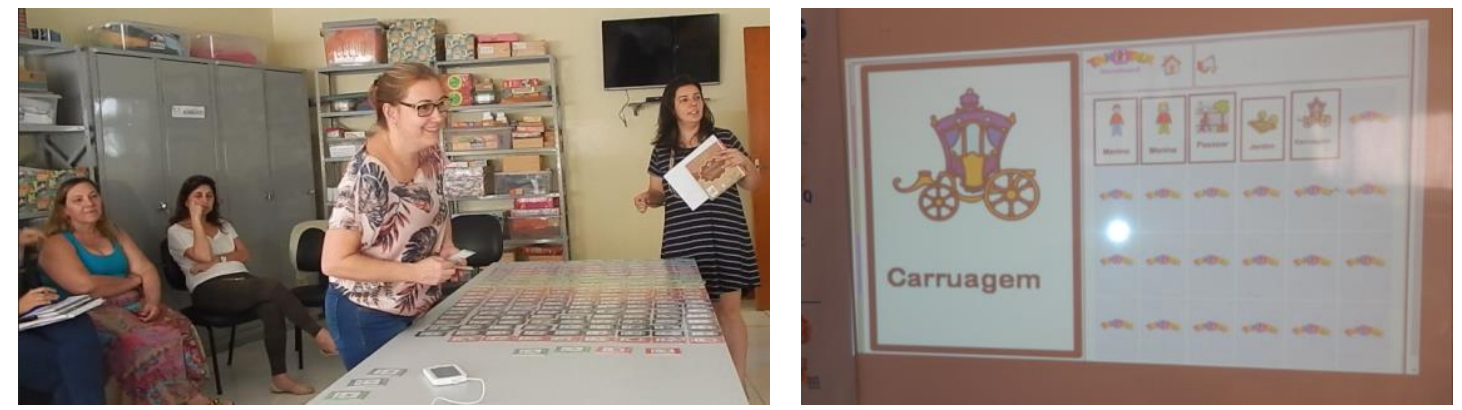

Figura 5. Proposta da atividade Sequência de ações: à esquerda, professoras realizando a dinâmica; à direita, projeção do Storyboard com um momento da atividade. 
VII Congresso Brasileiro de Informática na Educação (CBIE 2018)

Anais do XXIX Simpósio Brasileiro de Informática na Educação (SBIE 2018)

Essas três situações propostas são exemplos de atividades que podem ser feitas usando o Modo de Storyboard, embora essa funcionalidade proporcione a utilização em vários outros contextos, sejam eles assistivos ou pedagógicos. Como subsídio para isso, existe o Modo de Gerenciamento do sistema, que auxilia a criação de cartões relacionados às mais diversas disciplinas e temas, por exemplo, matemática, ciências etc., ampliando as possibilidades de utilização e comunicação.

Por meio das propostas de atividades feitas pelas participantes foi possível observar certas características do Modo de Storyboard. Na proposta 2, a quantidade de quadros (24) disponíveis na área de storyboard foi insuficiente para contar a história com todos os detalhes que as participantes desejavam, sugerindo uma mudança no design. Ainda, as participantes atentaram também para a necessidade da tradução para LIBRAS (Linguagem Brasileira de Sinais) das imagens e sugeriram que seja possível a exibição de um vídeo com a interpretação em LIBRAS do cartão de comunicação lido. A LIBRAS entraria como um reforço para a comunicação, como uma segunda língua para apoio à compreensão da linguagem oral.

\section{Conclusão}

Em nossos estudos temos utilizado um ambiente computacional tangível para apoio à comunicação, desenvolvido com base no design universal. $\mathrm{O}$ ambiente foi inicialmente planejado para ser utilizado sob a forma de um jogo de adivinhações. Porém, o ambiente possui potencial para uso em outros contextos, especialmente explorando aspectos do design para apoio à comunicação e interação entre alunos que encontram dificuldades para se fazer entender pela fala, e quaisquer outros interlocutores na escola comum. Neste trabalho conduzimos de forma participativa o redesign do ambiente inicial, denominado Tan2Talk, envolvendo professoras de AEE e sua prática cotidiana. As atividades foram realizadas no formato de Oficinas para explorar outras formas como o ambiente pode ser utilizado. Com base nos resultados iniciais, implementamos o Modo de Storyboard e o aplicamos em Oficinas realizadas junto a especialistas em educação especial, que propuseram três atividades que poderiam ser trabalhadas com crianças por meio desse novo modo do ambiente. A quantidade fixa de quadros para inclusão de imagens foi uma limitação, que deve ser resolvida em trabalhos futuros, juntamente com a inclusão de vídeo em LIBRAS referente a cada cartão de comunicação e a implementação da persistência das atividades, de maneira que as histórias, sequências, desafios e outras atividades que venham a ser realizadas por meio do Modo de Storyboard possam ser desenvolvidas em sala de aula. Ainda, o próximo passo no trabalho envolverá a utilização do novo modo do ambiente em Oficinas com crianças e suas professoras em sala de aula inclusiva; essa atividade possibilitará um aprofundamento nos temas do estudo e na análise qualitativa da efetividade do ambiente proposto.

\section{Agradecimentos}

Apoiaram este trabalho: Instituto Federal de São Paulo, CNPq (\#306272/2017-2), FAPESP (\#2015/16528-0), Secretaria de Educação de Amparo/SP, Instituto de Computação, Divisão de Educação Infantil e Complementar, Núcleo de Informática Aplicada à Educação e Grupo Gestor de Benefícios Sociais da Unicamp. 
VII Congresso Brasileiro de Informática na Educação (CBIE 2018)

Anais do XXIX Simpósio Brasileiro de Informática na Educação (SBIE 2018)

\section{Referências}

AmPARO. 2016. Secretaria Municipal de Educação. Programa de Educação Inclusiva : "A educação tem muitas faces - Educando e aprendendo na diversidade." 1-10. http://www.educaon.com.br/amp.

ASHA. 2016. American Speech-Language-Hearing Association. www.asha.org.

BRASIL. 2007. Ministério da Educação. Política Nacional de Educação Especial na Perspectiva da Educação Inclusiva. .

BRASIL. 2011. Casa Civil. Decreto No 7.611. Dispõe sobre a educação especial, o atendimento educacional especializado e dá outras providências. .

CHun, R.Y.S. 2009. Comunicação suplementar e/ou alternativa: abrangência e peculiaridades dos termos e conceitos em uso no Brasil. Pró-Fono Revista de Atualização Científica 21, 1, 69-74.

Garzotto, F. And Bordogna, M. 2010. Paper-based Multimedia Interaction as Learning Tool for Disabled Children. Interaction Design and Children Conference, 79-89.

Hengeveld, B., Hummels, C., Balkom, H. Van, Voort, R., And Moor, J. De. 2013. Wrapping Up LinguaBytes, For Now. 237-244.

Moita, F., Henrique, L., Candido, V., And Medeiros, F.M. 2017. Design e desenvolvimento de um game assistivo para autistas. XXVIII Simpósio Brasileiro de Informática na Educação, 1057-1066.

MoreirA, E.A. AND BARANAUSKAS, M.C.C. 2016. Investigando processos de comunicação alternativa via tecnologia tangível: um estudo exploratório. XXVII Simpósio Brasileiro de Informática na Educação, 856-865.

Moreira, E.A. AND BARANAUSKAS, M.C.C. 2018. Experimentando e Delineando um Vocabulário para um Ambiente Tangível de Apoio à Comunicação Alternativa e Aumentativa. .

PAPERT, S. 1980. Mindstorms: Children, Computers, and Powerful Ideas. New York.

SonzA, A.P., KAdE, A., FAÇAnHA, A., ET AL. 2013. Acessibilidade e Tecnologia Assistiva - Pensando a inclusão sociodigital de pessoas com necessidades especiais. Secretaria de Educação Profissional e Tecnológica/MEC, Bento Gonçalves, RS.

Tenor, A.C. AND DeliBerato, D. 2004. Estratégias de mediação para o conto e reconto de histórias para alunos surdos. Revista Educação Especial 29, 56, 681-694. 